\title{
Study of How Experience Involvement Affects Users' Continuance Intention to Use Mobile Reading
}

\author{
Qi WANG \\ Economics and Management School, Beijing University of Posts and Telecommunications, Beijing \\ 100876, China \\ E-mail: buptwangqi@bupt.edu.cn \\ Xiaoli ZHOU \\ Economics and Management School, Beijing University of Posts and Telecommunications, Beijing \\ 100876, China \\ E-mail: yudabajiaoli@126.com \\ Xiaohang ZHANG \\ Economics and Management School, Beijing University of Posts and Telecommunications, Beijing \\ 100876, China \\ E-mail: zhangxiaohang@bupt.edu.cn
}

\begin{abstract}
With the rapid development of mobile internet and the continuous replacement of new smart phones, the advancement of we-media age, and advent of the era of $4 \mathrm{G}$, reading revolution has opened. This paper is to study which factors affect users' continuance intention. We discussed the relationship between experience involvement, subjective norms, and the dimensions of perceived value as well as users' continuance intention. The results show that the model which this paper put forward could effectively explain the hypothesizes, and this paper mainly draws the following conclusions: subjective norm significantly affect experience involvement; on one hand, experience involvement significantly and directly affect users' continuance intention, and on the other hand, indirectly affect users' continuance intention by significantly affect the users' perceived usefulness, perceived pleasure and perceived cost; experience involvement can't significantly affect users' perceived image enhancement. We suggest the mobile reading providers pay more attention to the free experience process, increasing its convenience, enriching its content and rationalizing its cost. And they should also optimize the mobile reading to improve users' perceived image enhancement. Mobile reading providers should let users more involved to achieve value co-creation.
\end{abstract}

Keywords mobile reading; ECM-IT model; perceived value; users' continuance intention

\section{Introduction}

Along with rapid development of computer technology and network technology, digital information products have increasingly become the mainstream goods. Mobile reading is a typical

Received April 1, 2014, accepted September 1, 2014

Supported by National Social Science Fund Project (Grant No. 13CXW018); National Natural Science Foundation of China (Grant No. 71372194) 
example of digital information products. This paper will take mobile reading as an example to study the impacts of consumer involvement upon their continuous intention. Mobile reading is based on mobile phones (WAP, APP), tablets and E-books. Before reading, consumers can gratuitously experience 10 20 chapters, and such continuous experience is called as consumer involvement. Different involvements are highly related to purchase behavior, reflecting the higher one person's self-involvement of one thing and the higher possibility for acceptance of such products.

Today, due to rapid development of mobile Internet technologies and user's multiple choices, it is a difficult issue for sustained business development on how to retain customers and keep them to permanently use mobile reading. So it is very urgent to study the factors affecting mobile reading effect according to user's needs and reading contents.

\section{Literature review}

Fishbein and Ajzen ${ }^{[5]}$ proposed the theory of reasoned action (TRA) to predict whether human beings would be engaged in some actions. According to TRA, human's behavioral intention (BI) decides human's behavioral expression, and individual's attitude toward such behavior and subjective norms (SN) reflecting social impact can affect the BI and attitude. The more positive attitudes and subjective norms are, the higher the BI is, or vice versa ${ }^{[5]}$.

Technology acceptance model (TAM) is a theoretical model that Davis ${ }^{[3]}$ used TRA to study user's acceptance of information system, and it is an amendment of TRA. TAM introduces "perceived usefulness" and "perceived ease of use" to explain user's attitude and intention. Davis et al ${ }^{[18]}$ also introduced perceived enjoyment into TAM. In addition, it is discovered that perceived ease of use can, through the regulating roles of perceived enjoyment, affect the BI. After adding the perceived enjoyment variable, the model's explanatory power has been improved significantly.

Expectation confirmation theory (ECT) was proposed by Oliver ${ }^{[12]}$ on the basis of cognitive dissonance theory (CDT). According to ECT, customer's repeated purchase intentions are closely related to their past experience, and satisfactory experience is the key for them to establish long-term relationships with products or service suppliers. ECT is a basic theory to study consumer's satisfaction, as it elaborates the confirmation between expectation and perceived performance, and then judges whether customers are satisfied with products or services. Whereas, the satisfaction will be a reference for next purchase or use (repurchase intention). ECT has been widely used in the studies on customer satisfaction and repurchases intention. The expectation confirmation model (ECM) is shown in Figure 1.

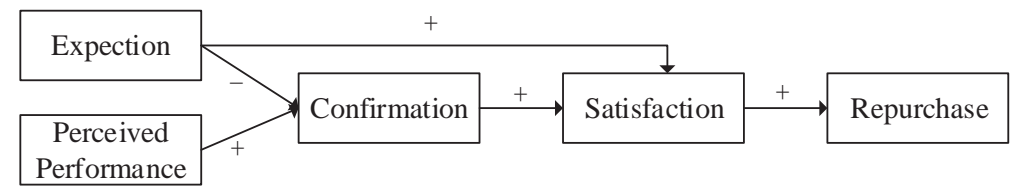

Figure 1 Expectation confirmation model

To make ECT more applicable to information system environment, Bhattacherjee ${ }^{[2]}$ also drew on Davis' TAM and then modified ECT, thus got ECM-IT for continuous use of information system, which is shown in Figure 2. 


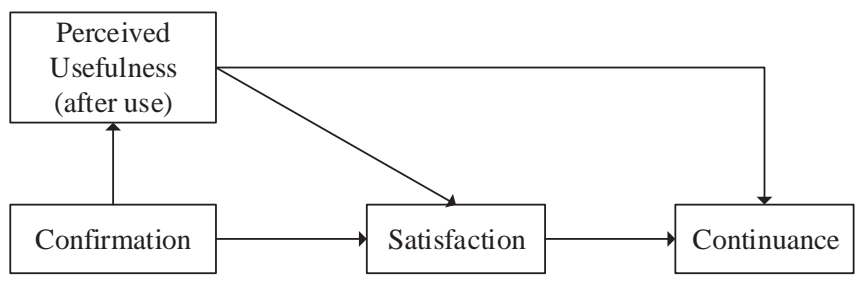

Figure 2 ECM-IT model

\section{Research model and assumptions}

\subsection{Research model}

According to theoretical overview, we can expand and amend specific connotation of expectation/belief variable in ECM-IT model, broaden the scope of research and improve the degree of explanation of the model, thus better predict and explain user's intention. In previous studies, some scholars indicated that consumer's expectations included the properties of products or services themselves, efforts made for the gains, costs and social benefits, so the connotation of expectation and user's perceived value was extremely similar. In addition, only with perceived usefulness and perceived ease of use as user's perception of mobile reading cannot reflect main features of mobile reading. As mobile reading is a content-based business, and its value is that the contents bring perceived values to users, but such value is undefined. Thus, the in-depth understanding of user's perceived value is helpful for enterprisers to carry out accurate value orientation and then better create values, playing dominated roles in the entire value network.

In this paper, user's perceived value based on mobile reading is considered as specific contents of expectation/belief variable after ECM-IT is used, namely, six dimensions of user's perceived value based on mobile reading are used to replace perceived usefulness in the ECMIT model. Meanwhile, this paper amends the ECM-IT model according to the characteristics of mobile reading, and also adds subjective norm factors in the model; furthermore, as user's satisfaction is constantly changing during mobile reading experience process, we cannot determine user's satisfaction after experience. Therefore, the variable of satisfaction is removed in this paper. The conceptual model in this study is shown in Figure 3.

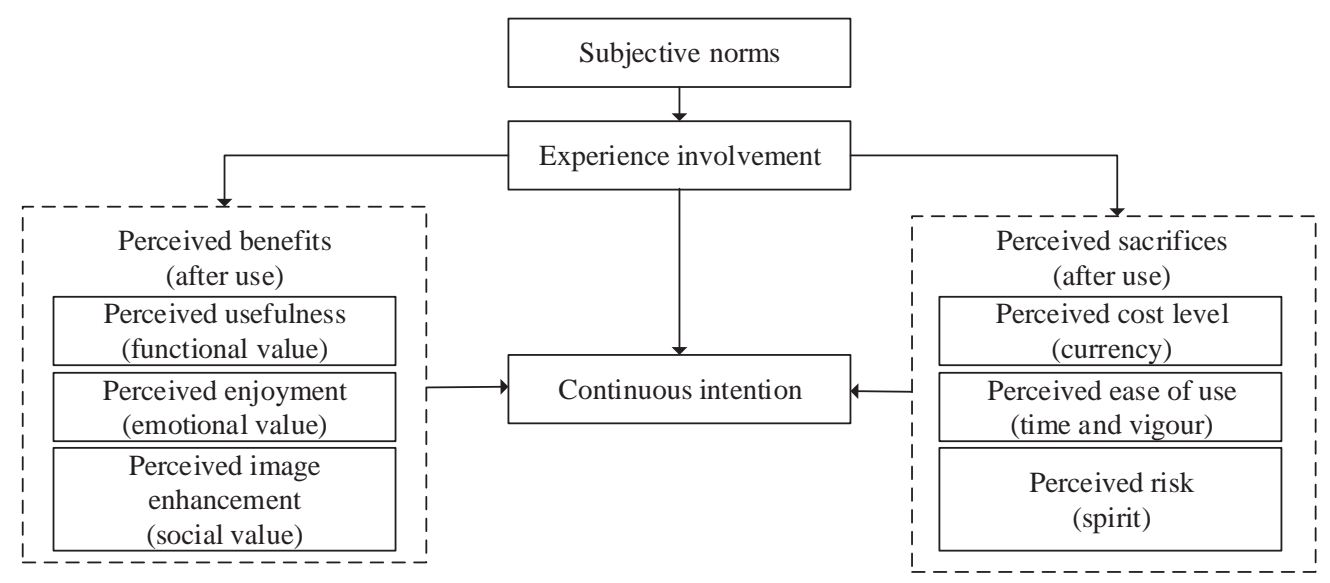

Figure 3 Research model 


\subsection{Definition of variables}

Subjective norms: perceived social pressure to perform or nor perform a behavior, a key component of the theory of reasoned action (TRA) ${ }^{[5]}$.

Experience involvement: The inconsistency between the expectation before using and perceived value after experiencing (Oliver). In this paper, we define experience involvement as the gap between the expectation before using mobile reading business and perceived value after experiencing mobile reading business.

Perceived usefulness (functional value): Users improve the performance after using mobile reading business;

Perceived enjoyment (emotional value): Users enjoy emotional pleasure in the use of mobile reading business; such enjoyment is related only to service process, but not related to the consequences;

Perceived image enhancement (social value): Users improve their personal images and social status after using particular mobile reading business;

Perceived cost level (currency): Subjective perception of objective prices for mobile reading business, that is, fairness and reasonableness of perceived prices;

Perceived ease of use (time and vigor): Make efforts (time and vigor) to achieve the objectives through particular mobile reading business;

Perceived risk (spirit): User's subjective perception of worrying about various losses brought by particular mobile reading business.

\subsection{Research Assumptions}

Subjective norm (SN) is the most widely used construct of social influence in IS acceptance theories. Schepers \& Wetzels suggest that in consumers context, SN is principally created by word-of-mouth. There is a significant body of evidence suggesting that SN plays an important role in affecting human behavior ${ }^{[1]}$. Previous research has found SN to have a positive direct effect on usage intention.

For mobile reading, experience is a kind of use, users' experience involvements mean their usage intention. Therefore we hypothesize that SN will have a significant positive effect on experience involvement.

H1: The greater the positive value of subjective norms, the higher the experience involvement, that is, subjective norms will significantly and positively affect the experience involvement.

Previous studies have shown that users will anticipate the product or service more from their own experience after usage ${ }^{[7]}$. Previous experience can help individuals more clearly and effectively evaluate the results. When users' expectation and usage are not consistent, they will be in psychological panic. Rational users will correct his initial expectations, making it closer to reality. The greater the positive value of experience involvement, the greater the users' anticipation of mobile reading, and vice versa. Therefore, experience involvement and the belief (after use) is positively related. Perceived image enhancement, perceived cost level and perceived risk are the contents of belief. So we put forward the following assumptions:

$\mathrm{H} 2$ : The greater the positive value of experience involvement, the higher the user's con- 
tinuous intention, that is, experience involvement will significantly and positively affect user's continuous intention.

H3c: The greater the positive value of experience involvement, the higher the perceived image enhancement (social value), that is, experience involvement will significantly and positively affect the perceived image enhancement.

H4a: The greater the positive value of experience involvement, the more reasonable the perceived cost level (currency), that is, experience involvement will significantly and positively affect perceived cost level.

H4c: The greater the positive value of experience involvement, the lower the perceived risk (spirit), that is, experience involvement will significantly and negatively affect the perceived risk.

Based on ECM-IT, many scholars, selecting mobile internet services, online software guide, web portal design, electronic negotiation system as the research object, have confirmed that experience involvement has positive effect on users' perceived usefulness, perceived enjoyment and perceived ease of use ${ }^{[2,14,16]}$. So our assumptions are as follows:

H3a: The greater the positive value of experience involvement, the higher the perceived usefulness (functional value), that is, experience involvement will significantly and positively affect the perceived usefulness.

H4b: The greater the positive value of experience involvement, the higher the perceived ease of use (the lower the perceived time and vigor), that is, experience involvement will significantly and positively affect the perceived ease of use.

H3b: The greater the positive value of experience involvement, the higher the perceived enjoyment (emotional value), that is, experience involvement will significantly and positively affect the perceived enjoyment.

Perceived value is an important index of users' repeated purchase intention. The perceived value can be divided into perceived benefits and perceived sacrifice. Perceived benefits include perceived usefulness (functional value), perceived enjoyment (emotional value), perceived image enhancement (social value), perceived cost level (currency), perceived ease of use (time and vigor), perceived risk (spirit). (currency). Thus, we propose that:

H5a: Perceived usefulness (functional value) exerts positive impacts upon user's continuous intention.

H5b: Perceived enjoyment (emotional value) exerts positive impacts upon user's continuous intention.

H5c: Perceived image enhancement (social value) exerts positive impacts upon user's continuous intention.

H6a: Perceived cost level (currency) exerts positive impacts upon user's continuous intention.

H6b: Perceived ease of use (time and vigor) exerts positive impacts upon user's continuous intention.

H6c: Perceived risk (spirit) exerts negative impacts upon user's continuous intention. 


\section{Research methodology}

In this paper, we use Likert7 to measure variables. Respondents are required to select strongly disagree, disagree, somewhat disagree, not sure, somewhat agree, agree and strongly agree according to their real mobile reading conditions, and then give 1 7 scores respectively. The latent and observed variables are shown in Table 1. For the objectivity of research, the investigated objects are identified as old users or active users. In consideration of youth's needs and interests on mobile reading business, this study mainly focuses upon 18 35 years old people with particular consumption power, coupled with a certain amount of users at other ages. We distributed 240 questionnaires totally, and recovered 181 effective questionnaires, thus the effective recovery rate is $75 \%$. Among the samples, there are 103 men, accounting for $56.91 \%$; and 78 women, accounting for $43.09 \%$. So the proportion between men and women is coordinated. This paper mainly uses SPSS19.0 analysis software to make preliminary analysis of surveyed data, and meanwhile adopts factor analysis and reliability analysis to verify the reliability and validity of data. Subsequently, we use AMOS18.0 structural equation approach to verify the data fitting and conceptual model, and also carry out relationship analysis between variables according to research results.

Table 1 Latent variables and observed variables

\begin{tabular}{|c|c|c|}
\hline Latent variables & Observed variables & References \\
\hline \multirow{3}{*}{ Subjective norms } & $\begin{array}{l}\text { I will be influenced by classmates and friends to use the mobile reading } \\
\text { continuously }\end{array}$ & {$[2]$} \\
\hline & $\begin{array}{l}\text { I will be influenced by opinions of the experts reported to use the mobile } \\
\text { reading continuously }\end{array}$ & \\
\hline & $\begin{array}{l}\text { I will be influenced by mobile reading community which I attended to } \\
\text { use the mobile reading continuously }\end{array}$ & \\
\hline \multirow{3}{*}{$\begin{array}{l}\text { Experience } \\
\text { involvement }\end{array}$} & $\begin{array}{l}\text { After experience of mobile reading, I found that it is better than I } \\
\text { expected }\end{array}$ & \\
\hline & After experience of mobile reading, I am sure about its perceived value & \\
\hline & $\begin{array}{l}\text { After experience of mobile reading, I am willing to continue to pay for } \\
\text { reading }\end{array}$ & \\
\hline \multirow{3}{*}{$\begin{array}{l}\text { Perceived } \\
\text { usefulness }\end{array}$} & The use of mobile reading can improve my personal efficiency & {$[3,4,10,16]$} \\
\hline & The use of mobile reading can make me read anytime and anywhere & \\
\hline & The use of mobile reading can make full use of fragmentary time & \\
\hline \multirow{3}{*}{$\begin{array}{l}\text { Perceived } \\
\text { enjoyment }\end{array}$} & When using the mobile reading, I feel time flies & {$[6,10]$} \\
\hline & $\begin{array}{l}\text { When using the mobile reading, I pay less attention to the noise around } \\
\text { than usual }\end{array}$ & \\
\hline & The use of the mobile reading is enjoyable process for me & \\
\hline \multirow{3}{*}{$\begin{array}{l}\text { Perceived image } \\
\text { enhancement }\end{array}$} & The use of the mobile reading can make me satisfied & {$[11,13]$} \\
\hline & The mobile reading can give me free space & \\
\hline & $\begin{array}{l}\text { The mobile reading makes me feel better than others, thus I like mobile } \\
\text { reading }\end{array}$ & \\
\hline
\end{tabular}


I think the cost of using mobile reading (including flow fee, messaging, [9, 13, 15]

Perceived cost etc.) is high

level Free experience reading is the main reason why I use mobile reading

Tariff level has influence on using mobile reading for me

\begin{tabular}{lll}
\hline \multirow{2}{*}{$\begin{array}{l}\text { Perceived ease } \\
\text { of use }\end{array}$} & I think the procedure of downloading mobile reading is simple & {$[3,4,10,17]$} \\
& I think operating mobile reading is simple \\
\hline
\end{tabular}

I worried that the use of mobile reading could leak my privacy $\quad[8,19]$

Perceived risk

I worried that the use of mobile reading could add unknown cost

I am afraid that when I need to use mobile reading, it might not work properly

I'm going to continue to use the mobile reading rather than a relevant $[2,16]$

user's continuous alternative business

intention I will always use mobile reading in the following days

I will renew more mobile reading service

\section{$5 \quad$ Reliability and validity analysis}

Reliability means the degree of stability and consistency of measured results. The higher the reliability, the lower the impact of measured scores due to errors. Generally, it is reliable if Cronbach's Alpha coefficient is greater than 0.6. Our test results show that Cronbach's Alpha coefficient of each variable is greater than 0.6 , indicating that measuring indictors of latent variables has reliable internal consistency.

Validity means the validity of test results, that is, researchers need to know whether the questionnaires are tested effectively. This study uses factor analysis method to verify the scale structural validity. Factor analysis needs to meet the following two conditions: Bartlett's Test of Sphericity and KMO (Kaiser-Meyer-Olkin) value identification.

After the above two tests, this study uses "principal component factor analysis" approach, and takes Varimax as a rotation way, eigenvalue $(>1)$ as the standard to choose the number of factors, and variable's factor loading $(>0.5)$ as the standard for factor analysis. This study will carry out independent factor analysis of questions relating to dependent variables in conceptual model, and also carry out factor analysis of questions relating to precursor variables in dependent variables. Table 2 shows the results of validity analysis.

Table 2 Reliability analysis of KMO and Bartlett's test

\begin{tabular}{lcc}
\hline \multicolumn{3}{c}{ Inspection of KMO and Bartlett } \\
\hline Sufficient sampling Kaiser-Meyer-Olkin measurements & .865 \\
\hline \multirow{3}{*}{ Bartlett's Test of Sphericity } & Df & 325 \\
& Sig. & .000 \\
\hline
\end{tabular}


From principal component factor analysis, we extract NINE common factors with eigenvalue greater than one. Eigenvalue of common factor 1 is 3.906, descending from 1 to 8, and the eigenvalue of common factor 9 is 4.561 . The accumulatively explanatory population variance of these nine factors is $83.145 \%$, as shown in Table 3 .

Table 3 Variance of overall explanation - Data after rotation

\begin{tabular}{cccc} 
Common factor & Eigenvalue after rotation & Explanatory variance (\%) & Accumulative proportion $(\%)$ \\
\hline 1 & 3.906 & 15.023 & 15.023 \\
2 & 3.416 & 13.138 & 28.161 \\
3 & 2.314 & 8.898 & 37.059 \\
4 & 2.228 & 8.571 & 45.630 \\
5 & 1.951 & 7.503 & 53.133 \\
6 & 1.846 & 7.101 & 60.234 \\
7 & 1.753 & 6.741 & 66.975 \\
8 & 1.678 & 6.574 & 73.549 \\
9 & 4.561 & 9.596 & 83.145 \\
\hline
\end{tabular}

The factor loading on associated variables is greater than 0.5 , with good convergent validity, showing good discriminant validity.

\section{Result analysis}

This paper uses structural equation to process the model, calculate standardized regression coefficients (path coefficient) and significance of each path, and builds the model's path relationship diagram, thus determine causal relationship between independent variables, intermediate variables and dependent variables. There are nine latent variables in the model, so we can use these 27 observable variables to indirectly measure these nine latent variables. AMOS' operating results give the model's commonly used fitting indicators, shown in Table 4.

Table 4 Fitting indicators for mobile reading user's continuous intention model

\begin{tabular}{ccccccc}
\hline Fitting indicator & Chi-square value & GFI & NFI & CFI & RMR & RMSEA \\
\hline Result & 451.243 & 0.925 & 0.913 & 0.936 & 0.017 & 0.038 \\
Evaluation standard & The smaller, the better & $>0.9$ & $>0.9$ & $>0.9$ & $<0.05$ & $<0.05$ \\
\hline
\end{tabular}

According to model indicators, the fitting degree of mobile reading user's continuous intention model is good, and all evaluation indicators are within the acceptable range. Therefore, such model is acceptable statistically.

This paper uses path analysis model of AMOS19.0 structural equation — recursive model assumptions for confirmatory analysis. Due to the assumption of recursive model, there is traceability relationship between variables. The result is in Table 5 .

It can be seen from the above table, the model's overall validation effect is better, and among 14 assumptions in the model, the significance of 10 assumptions has been verified.

From significance relationship of the assumptions, except that the influence significance of perceived ease of use on continuous intention, influence significance of perceived risk on continu- 
ous intention, influence significance of experience involvement on perceived image enhancement, and influence significance of experience involvement on perceived ease of use are larger than 0.05 ( $\mathrm{p}>0.05)$, the significance of other relationships is less than $0.05(\mathrm{p}<0.05)$.

Table 5 Result analysis of affecting factors of mobile reading user's continuous intentions

\begin{tabular}{lcccc}
\hline & Standardized & & & \\
& regression & S.E. & C.R. & P value \\
Assumption and path & coefficient & & & \\
\hline Continuous intention $\leftarrow$ Perceived usefulness & 0.362 & 1.079 & 3.871 & $* * *$ \\
Continuous intention $\leftarrow$ Perceived enjoyment & 0.405 & 0.805 & 3.763 & $* * *$ \\
Continuous intention $\leftarrow$ Perceived image enhancement & 0.123 & 0.407 & 2.801 & 0.006 \\
Continuous intention $\leftarrow$ Perceived cost level & 0.062 & 0.139 & 8.756 & $* * *$ \\
Continuous intention $\leftarrow$ Perceived ease of use & 0.241 & 0.603 & 3.287 & 0.120 \\
Continuous intention $\leftarrow$ Perceived risk & -0.085 & 0.054 & -3.294 & 0.320 \\
Continuous intention $\leftarrow$ Experience involvement & 0.478 & 0.036 & 2.271 & 0.012 \\
Perceived usefulness $\leftarrow$ Experience involvement & 0.615 & 0.136 & 4.758 & $* * *$ \\
Perceived enjoyment $\leftarrow$ Experience involvement & 0.734 & 0.106 & 0.975 & $* * *$ \\
Perceived image enhancement $\leftarrow$ Experience involvement & 0.597 & 0.140 & 4.792 & 0.076 \\
Perceived cost level $\leftarrow$ Experience involvement & 0.150 & 0.107 & 2.643 & $* * *$ \\
Perceived ease of use $\leftarrow$ Experience involvement & 0.213 & 0.118 & 4.735 & 0.191 \\
Perceived risk $\leftarrow$ Experience involvement & -0.054 & 0.034 & 1.496 & 0.046 \\
Experience involvement $\leftarrow$ Subjective norms & 0.325 & 0.057 & 2.709 & $* * *$ \\
\hline
\end{tabular}

In general, the model's overall validation effect is good. After removing non-significant assumptions, we can get the modified model as shown in Figure 4.

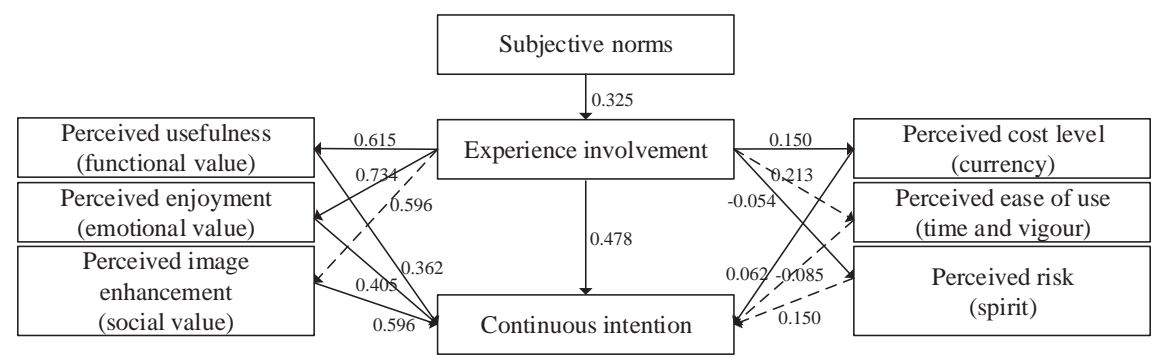

Figure 4 Significant structural variable chart

According to the results of AMOS19.0, we verified our hypotheses, and found that except that $\mathrm{H} 3 \mathrm{c}, \mathrm{H} 4 \mathrm{~b}, \mathrm{H} 6 \mathrm{~b}, \mathrm{H} 6 \mathrm{c}$ are false, other assumptions are true.

There are four non-significant relationships. First, Influence of experience involvement on perceived ease of use is not significant, because mobile reading is pretty convenient to download and operate, thus experience won't have great effects on consumers. Besides, for mobile reading, contents is the king. Operation and interface is less important than the usefulness and pleasure 
of its contents for mobile reading users. Therefore, the influence of perceived ease of use on continuous intention is not significant. And the influence of experience involvement on perceived ease of use is also not significant, the possible reason is that users' perception is changing all the time in the process of experience reading. As for the non-significant influence of perceived risk on continuous intention, the paper argues that at the present stage users mainly focus on the contents rather than risks like privacy and unknown charge. But with the further development of mobile reading, risks must be the main factors influencing users.

\section{Result analysis}

For mobile reading, reading several chapters for free is necessary for consumers to know if the content is worthy for them.

In this paper, we study the influential factors for continuous use of mobile reading business from the perspective of experience involvement. We build the variables from the perceived values and perceived efforts, establish the appropriate structural model based on extended ECM-IT theory, and then come to the following conclusions through verification: 1) Subjective norm significantly affect experience involvement, whereas experience involvement will significantly and directly affect user's continuous intention, and meanwhile indirectly affect user's continuous intention by affecting the perceived value of mobile reading business; 2) Experience involvement significantly affect user's perceived usefulness, perceived enjoyment, perceived cost level and perceived risks; 3) User's perceived usefulness, perceived enjoyment, perceived image enhancement and perceived cost level can significantly affect users' continuous intention for mobile reading business.

According to the above conclusions, we suggest the mobile reading providers pay more attention to the free experience process, increasing its convenience, enriching its content and rationalizing its cost. In this way, mobile reading providers can promote users' perceived usefulness, perceived enjoyment and perceived cost level which can affect users' continuous intention directly and significantly. But according to our findings, experience involvement can't significantly affect users' perceived image enhancement. Possibly because the current mobile reading can't give users the perception of image enhancement. Users' perceived image enhancement is very important under Maslow's need hierarchy theory, because image enhancement belongs to self-actualization, which is the highest need hierarchy of Maslow. So mobile reading providers should optimize their mobile reading to improve users' perceived image enhancement. We are now in the age of web2.0, users' sense of participation is an important sign. Mobile reading providers should let users more involved to achieve value co-creation. When users have read several chapters, they can set the rest framework of the novel, and other users can choose to agree or not. The author will refer to the users' vote, once the author adopted one of the users' advice, the user will act as a co-author. Thus, users' perceived image enhancement can be highly improved through their free experience process.

Our study is not only suitable for mobile reading, can also be applied to other areas, such as mobile phone manufacturing industry, e-commerce, etc. As mentioned above, sense of participation is very important, value co-creation is pretty hot, so our further study will focus on this field. 


\section{References}

[1] Ajzen I. Theory of planned behavior. Organization Behavior and Human Decision Processes, 1991, 50(2): 79-211.

[2] Bhattacherjee A, Premkumar G. Understanding changes in belief and attitude toward information technology usage: A theoretical model and longitudinal test. MIS Quarterly, 2004, 28(2): 229-254.

[3] Davis F D. Perceived usefulness, perceived ease of use, and user acceptance of information technology. MIS Quarterly, 1989, 13(3): 319-340.

[4] Eriksson K, Nilsson D. Determinants of the continued use of self-service technology: The case of Internet banking. Technovation, 2007, 27(4): 159-167.

[5] Fishbein M I, Ajzen B. Attitude, intention and behavior: An introduction to theory and research. MA: Addison-Wesley, 1975.

[6] van der Heijden H. User acceptance of Hedonic information systems. MIS Quarterly, 2004, 28(4): 695-704.

[7] Hsu M H, Chiu C M, Ju T L. Determinants of continued use of the WWW: An integration of two theoretical models. Industrial Management \& Data Systems, 2004, 104(9): 766-775.

[8] Hsu M H, Yen C H, Chiu C M, et al. A longitudinal investigation of continued online shopping behavior: An extension of the theory of planned behavior. International Journal of Human-Computer Studies, 2006, 64(9): 889-904.

[9] Kim H W, Chan H C, Gupta S. Value-based adoption of mobile internet: An empirical investigation. Decision Support Systems, 2007, 43(1): 111-126.

[10] Moon J W, Kim Y G. Extending the TAM for a World-Wide-Web context. Information \& Management, 2001, 38(4): 217-230.

[11] Moore G C, Benbasat I. Development of an instrument to measure the perceptions of adopting an information technology innovation. Information Systems Research, 1991, 2(3): 192-222.

[12] Oliver R L. A cognitive model of the antecedents and consequences of satisfaction decisions. Journal of Marketing Research, 1980, 17(4): 460-469.

[13] Petrick J F. Development of a multi-dimensional scale for measuring the perceived value of a service. Journal of Leisure Research, 2002, 34(2): 119-134.

[14] Roca J C, Chiu C M, Martinez F J. Understanding e-learning continuance intention: An extension of the technology acceptance model. International Journal of Human-Computer Studies, 2006, 64(8): 683-696.

[15] Sweeney J C, Soutar G N. Consumer perceived value: The development of a multiple item scale. Journal of Retailing, 2001, 77(2): 203-220.

[16] Thong J Y L, Hong S J, Tam K Y. The effects of post-adoption beliefs on the expectation-confirmation model for information technology continuance. International Journal of Human-Computer Studies, 2006, 64(9): 799-810.

[17] Venkatesh V, Davis F D. A theoretical extension of the technology acceptance model: Four longitudinal field studies. Management Science, 2000, 46(2): 186-204.

[18] Venkatesh V, Morris M G, Davis G B, et al. User acceptance of information technology: Toward a unified view. MIS Quarterly, 2003, 27(3): 425-478.

[19] Wood C M, Scheer L K. Incorporating perceived risk into models of consumer deal assessment and purchase intent. Advances in Consumer Research, 1996, 23(1): 399-405. 